\title{
Joint optimization of water allocation and water quality management in Haihe River basin
}

Martinsen, Grith; Liu, Suxia; Mo, Xingguo; Bauer-Gottwein, Peter

Published in:

Science of the Total Environment

Link to article, DOI:

10.1016/j.scitotenv.2018.11.036

Publication date:

2019

Document Version

Peer reviewed version

Link back to DTU Orbit

Citation (APA):

Martinsen, G., Liu, S., Mo, X., \& Bauer-Gottwein, P. (2019). Joint optimization of water allocation and water quality management in Haihe River basin. Science of the Total Environment, 654, 72-84.

https://doi.org/10.1016/j.scitotenv.2018.11.036

\section{General rights}

Copyright and moral rights for the publications made accessible in the public portal are retained by the authors and/or other copyright owners and it is a condition of accessing publications that users recognise and abide by the legal requirements associated with these rights.

- Users may download and print one copy of any publication from the public portal for the purpose of private study or research.

- You may not further distribute the material or use it for any profit-making activity or commercial gain

- You may freely distribute the URL identifying the publication in the public portal 


\begin{abstract}
A hydroeconomic optimization modelling framework for joint water allocation and water quality management is presented in this study. Water resources planning is often limited to water quantity, even though water quantity and quality are interdependent. Including water quality in a hydroeconomic optimization model increases complexity and uncertainty. In this study, the problem is addressed with a multi-reservoir, multi-temporal, multi-objective linear optimization model with fixed but spatially variable water quality. Model complexity is kept at a manageable level, leading to limited demand for computational resources, despite a high spatial resolution and representation of both surface water and groundwater resources. The model is applied to Haihe River basin, a water-scarce and highly polluted river basin in China. Economic trade-offs between limiting groundwater overdraft and sub-basin specific costs as well as maps of water availability shadow prices are presented. Adding water quality to the model framework impacts water availability shadow prices, which can influence model-based decision support. If groundwater abstractions are limited to sustainable levels, Haihe River basin will benefit from increasing inter-basins transfers and groundwater recharge to the shallow plain area aquifer. A scenario analysis showed that managed aquifer recharge in the plain area is also a feasible adaptation strategy.
\end{abstract}

Keywords: Hydroeconomic optimization. Integrated water resources management. China. Three Red Lines. Groundwater overdraft. Decision support.

\title{
1. Introduction
}

Increasing population and water demands have put pressure on the water resources in many regions around the world (Wada et al., 2014). Increased water scarcity often goes along with water quality deterioration. Water quantity and quality are strongly interlinked. River basin water quality is highly dependent on the hydrological system, human interactions with water bodies and upstream diffuse- and point sources of pollution that can be difficult to predict and monitor. In water resources management and planning, the use of optimization modelling can provide valuable insight. Hydrological modelling, economic valuation of 
water and mathematical optimization are combined to reveal economic trade-offs between water allocations in the model area, that can guide and inform decision makers. Including water quality in water resources optimization modelling increases uncertainty and water quality models are often very simple representations of reality (Loucks and van Beek, 2005). Consequently, it is not until late in the process of water resources planning that water quality is considered, if at all.

Applications of hydroeconomic optimization models are numerous, and the reader is referred to Harou et al. (2009) for an overview of modelling concepts and to Labadie (2004) for an extensive review of mathematical optimization for planning and operation in multi-reservoir systems. While single-reservoir studies can be useful to determine optimal reservoir operation, river basin scale water resources planning often requires optimization of several water sources and reservoirs. Stochastic Dynamic Programming (SDP) has been widely applied in hydroeconomic studies. Present costs of water allocations and expected future cost functions of predicted future water availability are solved in a recursive manner. The well-known curse of dimensionalities limits this application to a few reservoirs (Labadie 2004). Several methods, such as Stochastic Dual Dynamic Programming (SDDP), presented by Pereira and Pinto (1991), and genetic algorithms (GA) (Cai et al., 2001), have been used to overcome this limitation. In contrast to these approaches, the assumption of perfect foresight of future water availabilities significantly increases computational efficiency while allowing for a high number of reservoirs and water sources in the system representation. This assumption is widely used in applied river basin water resource planning modelling (Medellin-Azuara et al., 2018; AQUATOOL, 2018; DHI, 2018). However, the perfect foresight assumption fails to capture costs of unforeseen droughts and floods and the impact of hydrologic uncertainty on optimal decision making. In the design process of a hydroeconomic optimization model, model framework (e.g. modular vs. holistic framework, for a overview of the taxonomy the reader is referred to MacEwan et al. (2017)) as well as the model objective must be chosen wisely. The model framework must be suitable for the specific case study and the problem that needs to be addressed.

The literature includes much fewer studies on joint water quantity and quality optimization than on pure water quantity management. Optimization modelling considering water quality generally focus on either 
pollution minimizing management strategies or water allocation management to limit pollution loads. PeñaHaro et al., (2018) as well as Hsieh and Yang (2007) optimize according to groundwater pollution from agricultural fertilization practices and location of storm water pollution treatment facilities, respectively. Both studies simulate water quality as a response to various management strategies, which are optimized to meet quality constraints. Water quality standards can also be met from managing water allocations and their impact on instream water quality. Both Wang et al. (2009) and Davidsen et al. (2015) focus on water allocation management by accounting for return flow pollution loads, but with different approaches. Wang et al. (2009) consider water quality as one of three weighed objectives, and considers total water pollution from pollution load fractions from all water user allocations. Davidsen et al. (2015) introduce water quality to the model framework through downstream water quality constraints and simulates downstream pollution loads from upstream return flows, while considering groundwater management.

One region of the world that experiences pressure on its water resources is China. To address the deterioration of surface water quality, China introduced the 1989 Environmental Protection Law, the 2002 Water Law and the 2008 Law of Water Pollution Prevention and Control (Shen, 2012). As an implementation of these laws a system of surface water quality classes was developed in 1988, and reformulated in 2002 (MEP, 2002). The water quality classes define five classes with maximum tolerances to a broad range of water quality parameters. In the area known as North China Plain, an excessive overdraft of the regions groundwater resources has led to a dramatic decline in groundwater storage over the past decades (Feng et al., 2013). Alongside severe water scarcity, Haihe River basin, a part of the North China Plain, is the river basin in China with overall worst surface water quality. The surface water quality deterioration has reached a level where $36.8 \%$ of the monitored river network is polluted or highly polluted, with a surface water quality class of V or $>\mathrm{V}$, according to the Ministry of Environmental Protection 2016 statistics (Ministry of Environmental Protection 2016b). In 2015 the Water Ten Plan was launched, following the Three Red Lines policy document, that suggests a cap on total water consumption, improved water use efficiency and water pollution control. In the Water Ten Plan, Haihe River basin is one of the seven key river 
basins targeted for strategic water pollution control and water efficiency improvement, among others (China Water Risk, 2017).

Most studies of joint water quantity and quality management treat the two as non-linear dependencies. This study takes a different approach on joint optimization of water allocation and water quality management. In the highly polluted and water scarce Haihe River basin, a hydroeconomic model with fixed but spatially variable water quality was optimized to minimize total water associated costs. A flow path formulation (Cheng et al. 2009) was used to represent all possible water allocations from any water source to any connected downstream water user. Actual observed water qualities in Haihe River basin were assigned to each of these flow paths, also including groundwater abstraction flow paths. The model framework was optimized using a LP optimization algorithm under the assumption of perfect foresight. Water cleaning costs were assigned to the flow paths if the quality of a water source was inferior to the quality demand of a water user. The model was optimized over an eight year monthly planning period while successively constraining groundwater abstractions to a sustainable level. This enabled basin scale estimates of economic trade-offs from sustainable groundwater abstractions while accounting for the economic costs of meeting user quality demands over the whole basin. Taking into account water qualities altered cost-efficient water management strategies. These results can guide water resources decision makers in cost-benefit analyses of water infrastructure investments and reveal where in the river basin valuable opportunities for water augmentation exists.

\section{Methodology}

This article builds on a previously published hydroeconomic water allocation study of Haihe River basin by the same authors. For a more thorough explanation of the governing equations of the optimization problem, water resources and water demands estimates etc. the reader is referred to Martinsen et al. (2018). The monetary unit of the hydroeocnomic optimization model is expressed in Chinese yuan (¥). 


\subsection{Model framework}

The core of the model framework is a linear optimization solver, linking all available water resources to all water demands, under the constraints of Haihe River basin connectivity and water infrastructure. The optimizer minimized total monetary costs within the whole Haihe River basin over an eight-year planning period. It is a multi-temporal optimization setup, assuming perfect foresight over the full eight years. Monthly time steps were linked through surface water reservoir and groundwater aquifer water balances. The linear optimization problem can be simplified and generalized to a decision variable vector, $\mathrm{x}$, and a cost vector, $\mathrm{f}$, associating costs to all decision variables. The problem is subject to a series of linear inequality constraints, expressed as a matrix of decision variable coefficients, $\mathrm{A}$, and a right hand side vector, $\mathrm{b}$ as well as a matrix of coefficients Aeq, and the right hand side, beq, of all system equality constraints. Additional lower, $\mathrm{lb}$, and upper bounds, ub, apply to the model decision variables. The optimization problem can be solved accordingly:

$$
\min \left(f^{\prime} \cdot x\right)(1)
$$

s.t.

$$
\begin{gathered}
A \boldsymbol{e} \boldsymbol{q}=\boldsymbol{b e q}(2) \\
\boldsymbol{A} \leq \boldsymbol{b}(3) \\
\boldsymbol{l} \boldsymbol{b} \leq \boldsymbol{x} \leq \boldsymbol{u b}(4)
\end{gathered}
$$

The model was formulated as a flow path based linear programming problem. Based on Cheng et al. (2009) any decision of allocating water from a water source node to a downstream water demand node, in any time step, was formulated as a flow path decision variable in x. Compared to node based water balances, the flow path formulation significantly increase the number of decision variables. On the other hand the flow path formulation enables representation of parallel channels and bypasses, with different water qualities, which are characteristic for the water infrastructure in Haihe River basin. Demand deficits and the groundwater storages are additional elements in the decision vector. Equation (5) shows how the model water balances for the surface water reservoirs are flow path based and how allocations are linked in time:

$$
\sum_{i=1}^{n_{R S u p}} F P_{R S, t}=\sum_{i=1}^{n_{R S u p}} F P_{R S, t-1}-\sum_{i=1}^{n_{R R d o w n}} F P_{R R, t} \text { (5) }
$$


All ( $\mathrm{n}_{\mathrm{RSup}}$ ) flow path allocations to the reservoir storage, $\mathrm{FP}_{\mathrm{RS}}$ in time step $\mathrm{t}-1$, can be released to all downstream demands ( $\mathrm{n}_{\text {RRdown }}$ ) in time step $\mathrm{t}$, or released back into the reservoir storage in time step $\mathrm{t}$.

The groundwater aquifer systems of Haihe River basin were modeled as bucket storages, as in Equation (6). The groundwater aquifer storage, GRS, depends on the monthly recharge, $\operatorname{Re}_{\mathrm{GRS}, \mathrm{t}}$, and the sum of groundwater allocations, $\mathrm{FP}_{\mathrm{GRS}, \mathrm{t}}$, to all connected users, $\mathrm{n}_{\mathrm{GRSconnect}}$.

$$
G R S_{t}=G R S_{t-1}-\sum_{i=1}^{n_{G R S c o n n e c t}} F P_{G R S, t}+R_{G R S, t}(6)
$$

The methodology of linking groundwater resources to the water resources allocation problem, while also adhering to water quality demands is illustrated in Figure 1. It is shown for a single demand deficit equality constraint of the optimization model as in Equation (7). The deficit of user $\mathrm{i}$ in time step $\mathrm{t}$ is equal to the total demand minus the total flow path allocations of surface water $\left(\mathrm{FP}_{\mathrm{sw}}\right)$ and groundwater $\left(\mathrm{FP}_{\mathrm{GRs}}\right)$ :

$$
\text { Deficit }_{i, t}=\text { Demand }_{i, t}-\sum_{n=1}^{n_{F P, S W}} F P_{S w, n, i, t}-\sum_{n=1}^{n_{F P, G R S}} F P_{G R S, n, i, t} \text { (7) }
$$

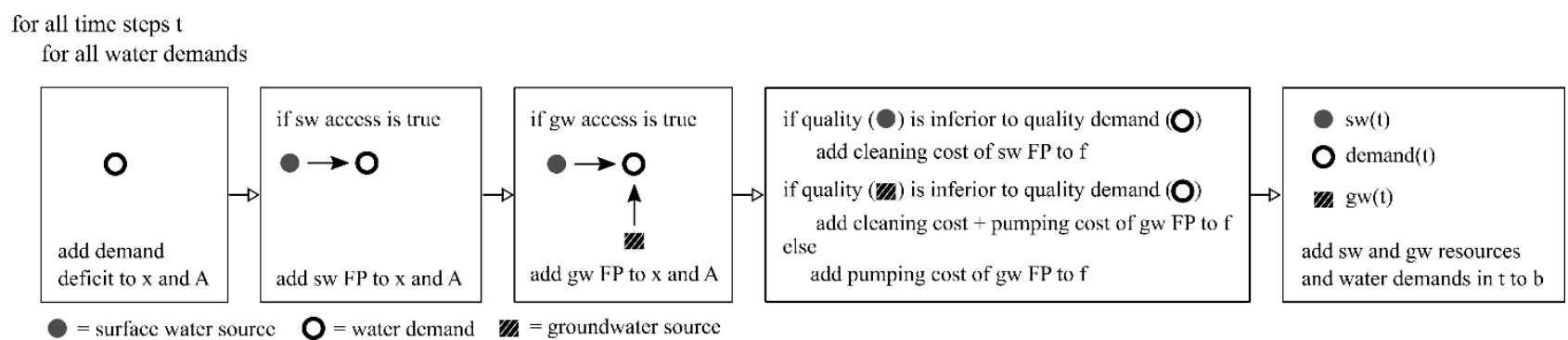

Figure 1. Conceptual illustration of the flow path based methodology for water allocation optimization of surface and groundwater resources while managing water quality demands.

An ArcGIS geometric network, linking all surface water source nodes to all downstream demand nodes, was post-processed using python to find all possible surface water flow paths. Using MATLAB, this information was combined with all possible groundwater flow paths connecting all water users with the appropriate groundwater aquifers. 


\subsection{Cost vector}

The cost vector, f, associates a curtailment cost to all deficits and a groundwater pumping cost to all groundwater flow paths. The pumping cost of the respective aquifer units are

$$
C_{\text {pump }}=p_{E} \cdot \rho \cdot g \cdot \frac{\Delta h}{\varepsilon}(8)
$$

Where $c_{\text {pump }}$ is the cost of pumping [yuan $\left./ \mathrm{m}^{3}\right], \mathrm{p}_{\mathrm{E}}$ is the price of electricity [yuan/J], $\rho$ is the density of water $\left[\mathrm{kg} / \mathrm{m}^{3}\right], \mathrm{g}$ is the gravitational acceleration $\left[\mathrm{m} / \mathrm{s}^{2}\right], \Delta \mathrm{h}$ is the lifting height, i.e. the average depth to the groundwater table [m] and $\varepsilon$ the pump efficiency [-].

If the quality of the source of the flow path, do not comply with the quality demand of the user served by that flow path, a cleaning cost was added to that specific flow path decision variable in the cost vector $\mathrm{f}$, as illustrated by Figure 1 .

\subsection{Model objectives}

Each model run was optimized according to a single objective. Performing multiple runs with constraints on secondary objectives enabled trade-off analysis between multiple objectives. In addition to the first objective of 1) minimizing total costs, a secondary objective 2) delivering water to end-users with qualities fit-forpurpose was ensured by the water quality check of all flow paths, adding cleaning costs for inferior water qualities. A third objective 3) reaching sustainable groundwater abstractions, was introduced through the constraining method. In the constraining method the end-storage constraints of the groundwater aquifers were gradually tightened. An unconstrained scenario, with unlimited groundwater abstraction identified the

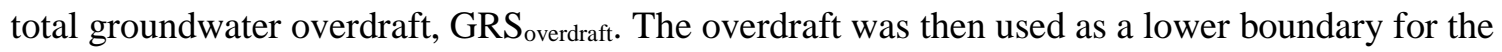
groundwater aquifer end-storage, $\mathrm{GRS}_{\text {end. }}$. The groundwater end-storage constraint was gradually tightened until a groundwater scenario with sustainable groundwater abstractions was reached, by running $\alpha$ from 1 to 0 :

$$
G R S_{\text {end }} \geq G R S_{t=0}-\alpha \cdot G R S_{\text {overdraft }} \text { (9) }
$$


Groundwater sustainability was defined as total abstraction being equal to total recharge over the full optimization period. The gradual tightening of the groundwater end-storage constraints resulted in an ensemble of eleven groundwater scenarios ranging from unlimited overdraft to sustainable groundwater abstractions.

\subsection{Surface water resources and water demands}

All available water resources and agricultural water demands were computed for an eight-year period, with meteorological forcing data from $1^{\text {st }}$ of January 2007 to $1^{\text {st }}$ of January 2015.

\section{Rainfall-runoff modelling}

Daily time series of precipitation and evaporation from the gridded meteorological data of China Meteorological Agency (China Meteorological Agency, 2017) were used to compute sub-basin specific monthly time series of precipitation and evapotranspiration over the period 1971 to 2016. Monthly precipitation and evapotranspiration were used to calibrate a Budyko rainfall-runoff model (Zhang, 2008) for the mountainous runoff-generating sub-basins. Three minor sub-basins within Haihe River basin were calibrated against observed runoff (Ministry of Water Resources, 2011) by split-sample calibration over the 20 year period 1971-1991. The model parameters were validated by proxy-basin validation over the period 2006-2011.

\section{Water demands}

Each sub-basin has seven categories of water demands. These are (1) domestic, (2) industry, and agricultural subcategories of (3) double cropping of wheat and maize, (4) single cropping maize, (5) single cropping wheat, (6) orchards and (7) vegetables. Domestic and industrial demands were based on China Statistical Yearbook data for Hebei, Beijing and Tianjin provinces (National Bureau of Statistics of China, 2015). The sub-basin specific water demands for these two categories were estimated by population scaling using the Landscan 2016 population count (Bright et al., 2017). The agricultural water demands were estimated based on the FAO 56 method (Allen et al. 1998). Monthly water demands were found for each cultivated area, $A_{c}$, 
using local crop specific coefficients, $\mathrm{K}_{\mathrm{c}}$, and monthly precipitation and evapotranspiration time series, $\mathrm{P}$ and $\mathrm{ET}_{0}$, for each time step, t:

$$
\operatorname{Dem}_{a g r, t}=A_{c} \cdot\left(E T_{0, t} \cdot K_{c, t}-P_{t}\right)(10)
$$

\section{Input data}

\subsection{Haihe River basin connectivity and water infrastructure}

Spatially, the model of Haihe River basin was divided into 16 sub-basins (numbered 1 to 16 in Figure 2). Watershed delineation in ArcGIS was used to define the sub-basins. Nine sub-basins were defined upstream the major reservoirs with capacities above 1,000 mio $\mathrm{m}^{3}$ identified from the Global Reservoir and Dam data set (GRanD) (Lehner et al., 2011). These were Panjiakou, Miyun, Guanting, Xidayang, Wangkuai, Gangnan, Huangbizhuang and Yuecheng reservoirs. Runoff was generated in these nine sub-basins in the western and northern mountainous regions of Haihe River basin. Further division of the downstream plain area into seven additional sub-basins was done and aligned with the official Ministry of Water Resources publications (Ministry of Water Resources, 2011). Separate sub-basins defines the administrative province borders of Beijing and Tianjin province. 


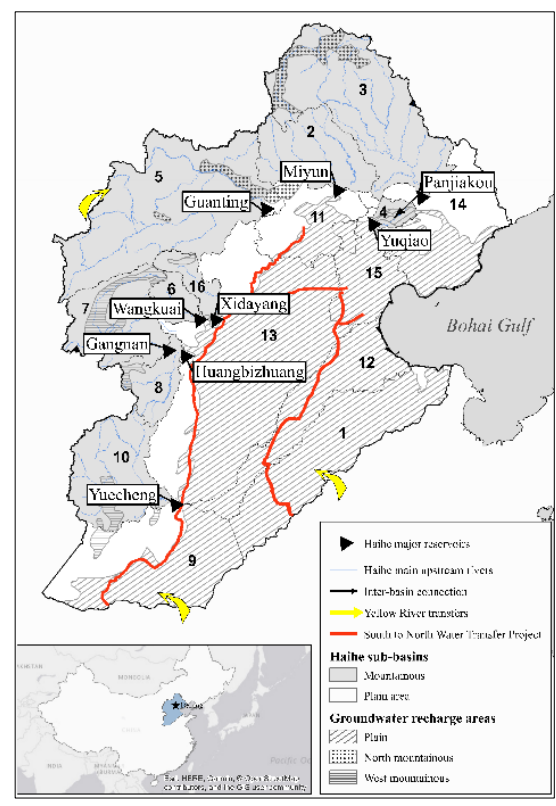

Figure 2. Conceptual illustration of Haihe River basin, the sub-basins, surface water reservoirs, groundwater recharge areas and inter-basin transfers.

\subsection{Groundwater resources}

Groundwater was assumed to be available in areas of surface-near quaternary deposits. From a USGS geological map (Steinshouer et al., 1997) a major recharge area on the plain and minor mountainous recharge areas were identified. The groundwater resources of Haihe River basin were divided into northern mountainous, the western mountainous and the shallow and deep plain area groundwater resources, see Figure 2. A detailed hydrogeological cross section of the Haihe River basin plain area can be found in Figure 2 in Cao et al. (2013), showing the separation of the plain area aquifer into a shallow and a deeper unit by a confining layer. All users of model sub-basins overlapping with the extent of the groundwater recharge area were connected users, which could access the groundwater resources of that aquifer. Large-scale groundwater recharge rates were mostly available for the major groundwater system in the plain area of the model. Assuming mountainous recharge occurring mainly in areas of similar geology as the plain area, allowed transfer of the overall recharge rate found in literature. Recharge to the groundwater aquifers of the mountainous regions were found by multiplying mountainous precipitation with the scaling coefficient between plain area precipitation and shallow groundwater recharge. Because of the limited extent of the 
mountainous aquifers, abstraction from the mountainous groundwater aquifers were subject to a yearly sustainable groundwater aquifer water balance constraint. The water balance of the larger plain area aquifer spans the whole optimization period, subject to the constraining method explained in Section 2.3.

The estimated groundwater recharge areas, rates and groundwater pumping costs for each of the four groundwater aquifer units of the model are seen in Table 1.

Table 1. Groundwater aquifer recharge areas (Steinshouer et al., 1997), recharge rates (Kendy et al. 2003; Shu et al. 2012; Cao et al. 2013) and pumping costs.

\begin{tabular}{llll}
\hline Groundwater aquifer & Recharge area $\left[\mathbf{k m}^{\mathbf{2}}\right]$ & $\begin{array}{l}\text { Recharge rate } \\
\text { [mm/year] }\end{array}$ & $\begin{array}{l}\text { Pumping cost } \\
{\left[\mathbf{y u a n} / \mathbf{m}^{3} \text { ] }\right.}\end{array}$ \\
\hline GRS $_{\text {plain,shallow }}$ & 141,398 & 96 & 0.1 \\
GRS $_{\text {plain,deep }}$ & - & 24 & 0.8 \\
GRS $_{\text {north }}$ & 6,648 & 92 & 0.4 \\
GRS $_{\text {west }}$ & 7,673 & 115 & 0.4 \\
\hline
\end{tabular}

\subsection{Inter-basin surface water transfers}

Haihe River basin receives additional surface water resources from inter-basin transfers from the Yellow River and the South to North Water Transfer Project (SNWTP). The SNWTP routes through Haihe River basin and the Yellow River transfer inlets are indicated on Figure 2. The yearly estimated inter-basin transfers into Haihe River basin can be seen in Table 2.

Table 2. Inter-basin transfer into Haihe River basin. SNWTP capacities based on NSBD (2001a and 2001b). Yellow River transfers estimated based on Wang et al. (2015)

\begin{tabular}{llllll}
\hline SNWTP & SNWTP & Yellow River & Yellow River & Yellow \\
east & mid & east & mid & River into \\
& & & & Jin \\
\hline
\end{tabular}




\begin{tabular}{llllll}
\hline Water transfers [mio m $\mathrm{m}^{3}$ year $]$ & 2,000 & 5,700 & 1,490 & 1,490 & 1,490
\end{tabular}

\subsection{Water quality data}

The surface water qualities were classified according to the Chinese Environmental Quality Standards for Surface Water (MEP, 2002). The surface water quality classes range from a quality class I of good quality to a quality class of $\mathrm{V}$ of bad quality. These classes apply as minimum quality standards for different purposes of water use (Table 3).

Table 3. Chinese Environmental Quality Standards for Surface Water (MEP, 2002).

\begin{tabular}{ll}
\hline Surface water quality class & Qualify for use in \\
\hline II & First class protected areas of surface water sources for centralized drinking \\
& water \\
\hline III & Ecological demands (winter fishing grounds of fish and shrimp, migratory \\
& passages, aquaculture areas and other fishing waters and swimming areas) \\
\hline IV & General industry \\
\hline V & Agriculture \\
\hline
\end{tabular}

Institute of Public and Environmental Affairs (IPA, 2006) has mapped around 380 monitoring stations in Haihe River basin with surface water quality class observations ranging from single observations to yearly and weekly time series. In total 109 monitoring station were selected, ranked according to quality and observation frequency (1: Yearly or less, 2: Monthly, 3: Weekly), and used to determine the flow path source water quality classes (Figure 3). The resulting sub-basin water quality defines the water source qualities of the surface water flow paths. The water qualities of the SNWTP mid and east line are of quality class II and III respectively (MEP, 2016a). The water qualities of Yellow River inter-basin transfers are of quality class III (IPA, 2006). 


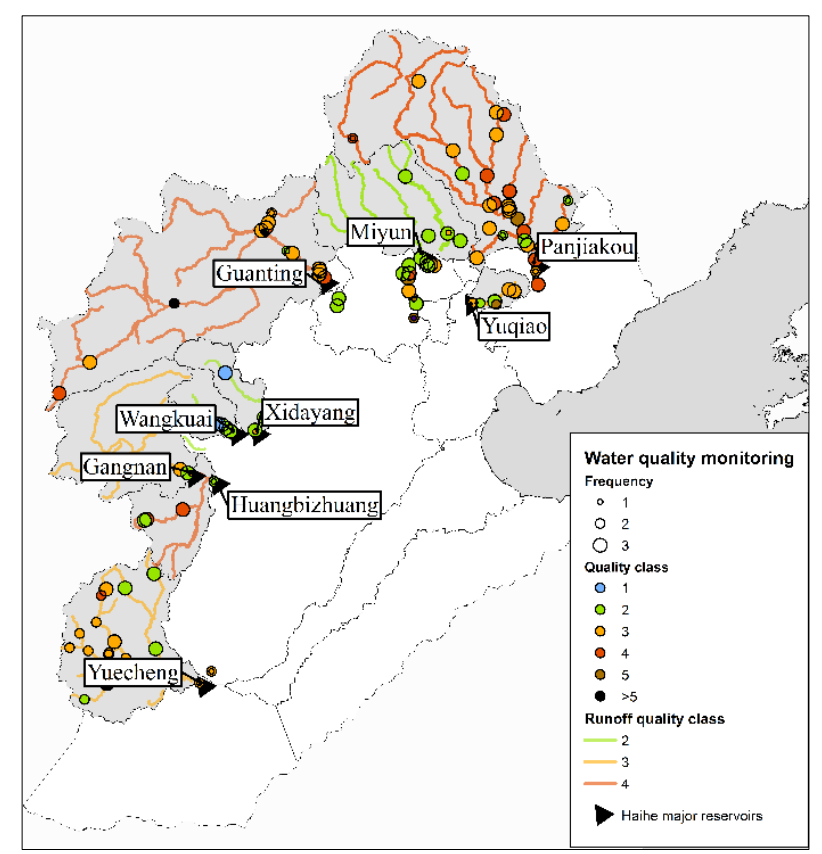

Figure 3. Surface water monitoring stations' average quality class and monitoring frequency, and overall sub-basin surface water quality classes. Based on monitoring data from IPA (2006).

For groundwater qualities, data is sparser. Groundwater flow path qualities were based on reports by the Ministry of Environmental Protection. Generally the shallow plain aquifer is of lower quality compared to the deeper layers (Tan et al., 2015; MEP, 2011). The model flow paths leaving the shallow aquifer unit was assumed to have a quality class of $\mathrm{V}$, only fit for agricultural groundwater allocations. The deep aquifer unit was assumed to have a quality class II. According to the Ministry of Environmental Protection the mountainous groundwater resources are of better quality than the plain area aquifer (MEP, 2011) and were assigned a general good quality of class II.

\subsection{Cleaning and deficit costs}

The cleaning costs are unique for each sub-basin and come from local wastewater cleaning fees (China, 2000). Averaged local wastewater cleaning fees used in the model can be found in Table 4 . The costs of cleaning water deliveries to comply with quality standards were assumed to be equal no matter how many quality classes the source was inferior to the downstream quality demand. 
Table 4. Sub-basin (seen in Figure 2) average cleaning costs of water allocations, January 2017. Based on (H2O China, 2000).

\begin{tabular}{lcccccccccccccccc}
\hline Sub-basin & $\mathbf{1}$ & $\mathbf{2}$ & $\mathbf{3}$ & $\mathbf{4}$ & $\mathbf{5}$ & $\mathbf{6}$ & $\mathbf{7}$ & $\mathbf{8}$ & $\mathbf{9}$ & $\mathbf{1 0}$ & $\mathbf{1 1}$ & $\mathbf{1 2}$ & $\mathbf{1 3}$ & $\mathbf{1 4}$ & $\mathbf{1 5}$ & $\mathbf{1 6}$ \\
\hline Cleaning cost & 0.6 & 0.7 & 0.7 & 0.7 & 1.0 & 0.9 & 0.9 & 0.7 & 0.8 & 0.6 & 1.6 & 0.9 & 1.0 & 1.7 & 1.1 & 0.9 \\
& & & & & & & & & & & & & & & & \\
{$\left[y u a n / \mathrm{m}^{3}\right]$} & & & & & & & & & & & & & & & & \\
\end{tabular}

Unit costs of water user deficits for all 16 sub-basins are found in Table 5.

Table 5. Curtailment costs of water demand deficits for each of the 16 model sub-basins, seen in Figure 2. 1) Gan et al. (2008), 2) H2O China (2000), 3) World Bank (2001).

\begin{tabular}{|c|c|c|c|c|c|c|c|c|c|c|c|c|c|c|c|c|}
\hline Sub-basin & 1 & 2 & 3 & 4 & 5 & 6 & 7 & 8 & 9 & 10 & 11 & 12 & 13 & 14 & 15 & 16 \\
\hline Low value crops ${ }^{1)}$ & 1.8 & 1 & 1.3 & 1.3 & 1.6 & 1.6 & 1.2 & 1.2 & 1.6 & 1.2 & 1 & 1.8 & 3.3 & 1.3 & 1 & 1.6 \\
\hline High value crops ${ }^{1)}$ & 13.6 & 7.4 & 12.3 & 12.3 & 24.7 & 24.7 & 39.2 & 39.2 & 14.95 & 39.2 & 7.4 & 13.6 & 14.2 & 12.3 & 7.4 & 24.7 \\
\hline Domestic $^{2)}$ & 2 & 2.7 & 2.7 & 2.7 & 2.6 & 2.3 & 2.3 & 2.5 & 2.1 & 2.6 & 5 & 4 & 3.2 & 3.5 & 4.9 & 2.3 \\
\hline Industry $^{2)}$ & 2.4 & 5.6 & 5.6 & 5.6 & 4.2 & 3.1 & 3.1 & 3.9 & 2.8 & 4.8 & 9.9 & 6.3 & 4.7 & 5.9 & 7.9 & 3.1 \\
\hline Ecological $^{3)}$ & 1.5 & 1.5 & 1.5 & 1.5 & 1.5 & 1.5 & 1.5 & 1.5 & 1.5 & 1.5 & 1.5 & 1.5 & 1.5 & 1.5 & 1.5 & 1.5 \\
\hline
\end{tabular}

\section{Results and discussion}

\subsection{Computational resources}

The optimization problem spanned an eight-year period with 1,722 monthly decision variables that summed totally 165,312 decision variables. The CPU time required to solve the full ensemble of eleven groundwater scenarios was $\sim 46$ seconds in a 2 Intel ${ }^{\circledR}$ Core ${ }^{\mathrm{TM}}$ i5-7200U processor with 8 GB RAM and Windows 7 operating system. Computational resources are therefore not a limiting factor in increasing the spatial resolution of the model area. A spatially much more aggregated modelling study of a single surface water reservoir and one groundwater aquifer, and considering stochastic future inflow, was carried out by Davidsen et al. (2016) to study groundwater sustainability in Ziya River basin, North China Plain. The SDP model solved in a coupled LP-GA optimization setup was reported to use 4000 CPU hours to solve a single 
scenario. This clearly illustrates the trade-off between spatial model complexity and considering unforeseen future water availability in the choice of model framework.

\subsection{Pareto front}

For each of the eleven groundwater scenarios the total costs consisting of user curtailment costs, groundwater pumping costs and water treatment costs were quantified. Combining all of the groundwater scenarios made up the Pareto front (Figure 4). The slope of the front shows the economic trade-off between limiting total costs and ensuring groundwater sustainability. It should be noted that model results are to be seen as lower boundaries of total water-associated costs, and not absolute values. Two Pareto fronts are illustrated, one with a joint optimization of water allocations and water qualities, and one solely managing water quantities. The difference between the two Pareto fronts quantifies minimum costs of ensuring water qualities fit for purpose in Haihe River basin. This difference ranged from 0.29 to 1.2 billion yuan/year depending on the groundwater scenario. The total groundwater allocations for each groundwater scenario are also shown, along with the relative abstraction from the shallow and the deep plain aquifer. The initial adaptation strategy, when moving away from groundwater overdraft, was a shift from the over-pumped shallow aquifer to deep groundwater abstractions, sustaining constant total groundwater abstractions. At the point where approximately $25 \%$ of total plain area groundwater abstractions came from the deep aquifer unit, a decrease in total groundwater abstractions was necessary to reach a sustainable abstraction scenario. At present, the deep groundwater aquifers of Haihe River basin are exploited to a significant degree. The mark "present”, between the unlimited overdraft scenario and sustainable groundwater abstractions, on the Figure $4 \mathrm{x}$-axis represents a groundwater allocation situation of today. As groundwater abstractions were limited to a sustainable level, the costs increased significantly from curtailment of users, and allocation schemes had to adapt in the most cost-efficient way in order to keep costs low. The relative cost of reaching sustainable groundwater allocations compared to a present scenario was 12.2 bio yuan/year when considering water qualities. Scaling up results from the Davidsen et al. (2016) study on Ziya River basin (a sub-basin of Haihe River basin) to the Haihe River basin population count gives a cost estimate of 32.8 billion yuan/year. This is comparable to the cost in this study's sustainable groundwater scenario, of 26 billion yuan/year (Figure 4). 
The total cost estimate of this study is expected to be lower since pumping costs are not head-dependent and the possible cost-efficiency gained from possible substitutions of water resources between the Haihe River sub-basins in the model setup.

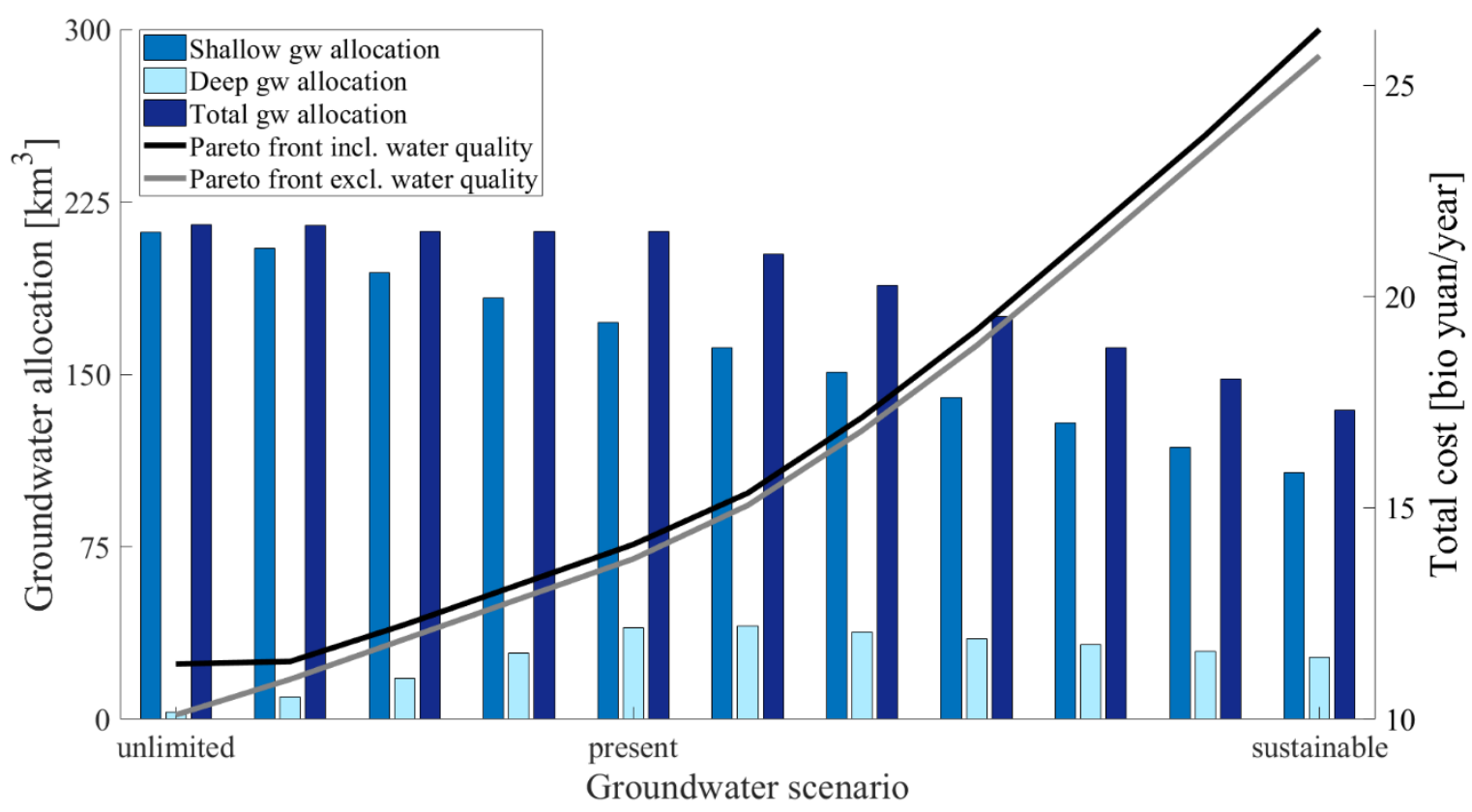

Figure 4. Pareto fronts and groundwater allocation under the transition from an unlimited to a sustainable abstraction scenario.

\subsection{Spatial cost distribution}

The model provided the spatial distribution of costs across the Haihe River basin, in the optimal solution. The results seen in Figure 5 are from one of the multiple equally optimal solutions. The spatial pattern of sub-basin costs was stable between different equally good solutions.

As expected, limiting groundwater overdraft increased total costs, especially in the plain area, where the major costs originated from demand deficits. The highest costs from demand deficits were seen in sub-basin 3, 5, 9 and 14. Sub-basin 9 and 14 are the most isolated sub-basins in the plain area with regards to water infrastructure, and sub-basin 14 has a relatively high water treatment cost. Sub-basin 3 and 5 have some of the most polluted surface waters and a low water availability to water demand ratio. 
Costs originating from groundwater pumping and cleaning were highest in the plain area sub-basins. The total costs in Haihe River basin from groundwater pumping and cleaning were 3.8, 6.7 and 4.6 billion yuan/year for the unlimited, present and sustainable groundwater scenario, respectively. One could expect that less total groundwater abstraction would cause less costs, but the costs from pumping and cleaning groundwater was actually higher in the sustainable scenario compared to a scenario with unlimited overdraft. Saving groundwater was not strictly equivalent to lower costs of delivering groundwater. The groundwater costs were highly driven by the fraction of deep, and more expensive, aquifer pumping. From the present scenario to the sustainable abstraction scenario, the groundwater costs decreased because of less total pumping.

In the unlimited overdraft scenario the surface water cleaning costs summed up to 0.68 billion yuan/year, going to 0.09 billion yuan/year in the present groundwater scenario ending up with a total surface water cleaning cost of 0.11 billion yuan/year in the sustainable groundwater scenario. The occurrence of costs shifted from the mountainous regions to the downstream plain areas that became more dependent on the upstream polluted surface water when the groundwater abstractions were limited. The cleaning cost of plain area sub-basin 1 is lower than the deep aquifer pumping costs and the sub-basin therefore had significant surface water cleaning costs even in the unlimited groundwater abstraction scenario. Compared to the costs originating from user deficits and groundwater pumping, the cleaning costs were magnitudes smaller. This is an effect of the highly engineered and complex water infrastructure of Haihe River basin combined with an optimization-based model. As the plain area received more of the polluted surface water runoff, the flexibility in downstream user allocations allows the optimization model to allocate water where it is most fit for purpose in terms of qualities, avoiding excessive cleaning costs. 


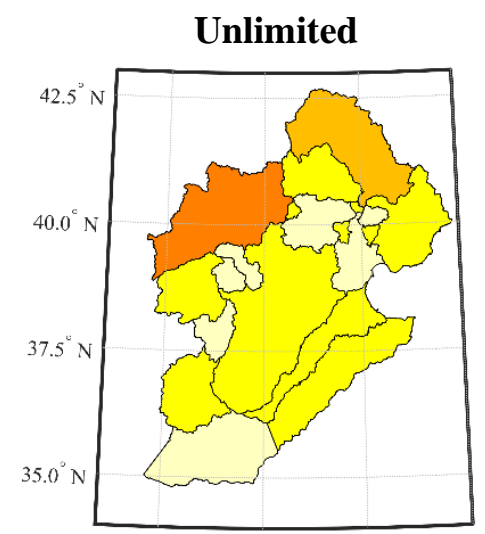

$\begin{array}{llll}112.5^{\circ} \mathrm{E} & 115.0^{\circ} \mathrm{E} & 117.5^{\circ} \mathrm{E} & 120.0^{\circ} \mathrm{E}\end{array}$

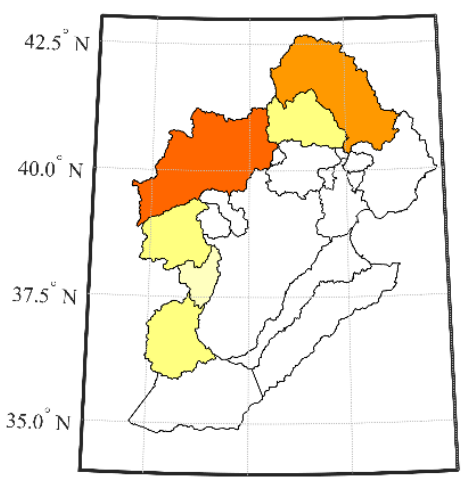

$\begin{array}{llll}112.5^{\circ} \mathrm{E} & 115.0^{\circ} \mathrm{E} & 117.5^{\circ} \mathrm{E} & 120.0^{\circ} \mathrm{E}\end{array}$
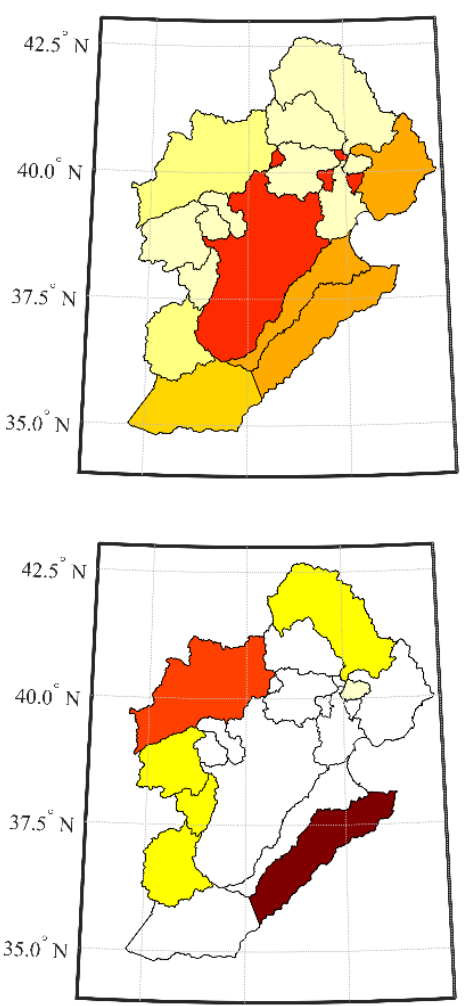

$\begin{array}{llll}112.5^{\circ} \mathrm{E} & 115.0^{\circ} \mathrm{E} & 117.5^{\circ} \mathrm{E} & 120.0^{\circ} \mathrm{E}\end{array}$
Present

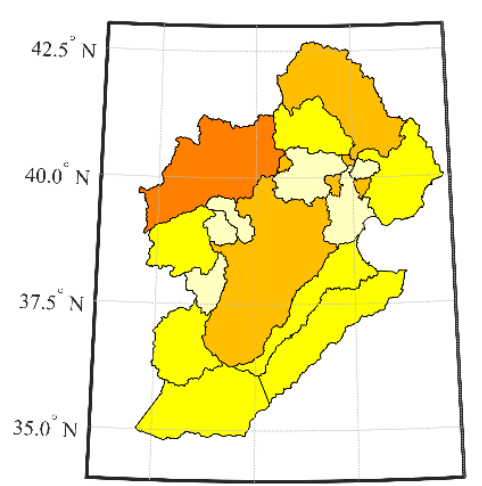

$112.5^{\circ} \mathrm{E} \quad 115.0^{\circ} \mathrm{F} \quad 117.5^{\circ} \mathrm{E} \quad 120.0^{\circ} \mathrm{E}$

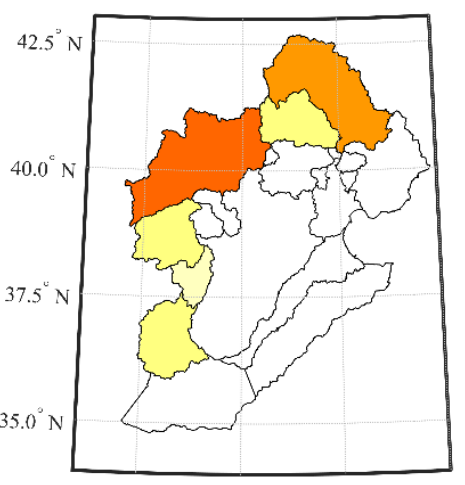

$112.5^{\circ} \mathrm{E} \quad 1150^{\circ} \mathrm{E} \quad 1175^{\circ} \mathrm{E} \quad 120.0^{\circ} \mathrm{E}$
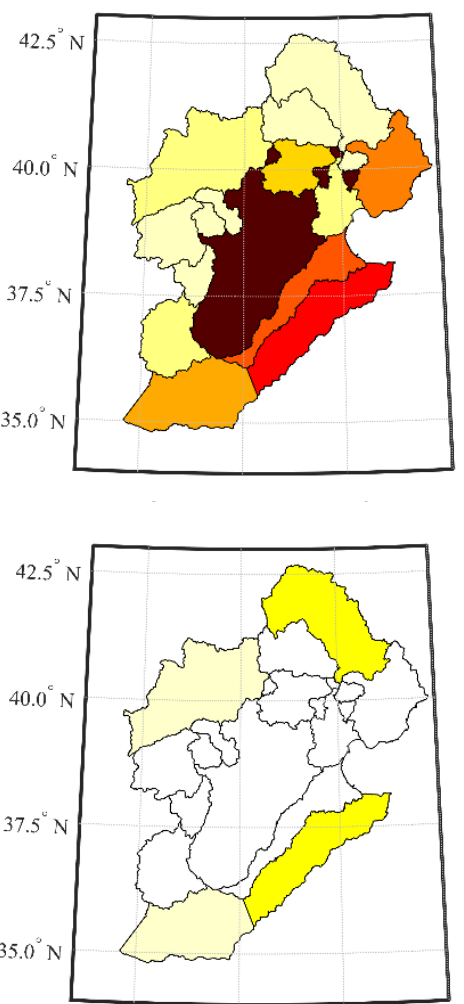

$112.5^{\circ} \mathrm{E} \quad 115.0^{\circ} \mathrm{E} \quad 117.5^{\circ} \mathrm{E} \quad 120.0^{\circ} \mathrm{E}$
Sustainable

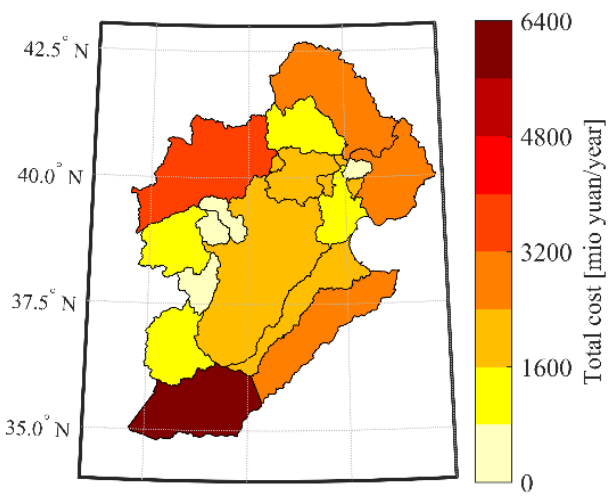

$112.5^{\circ} \mathrm{E} \quad 115.0^{\circ} \mathrm{F} \quad 117.5^{\circ} \mathrm{E} \quad 120.0^{\circ} \mathrm{E}$

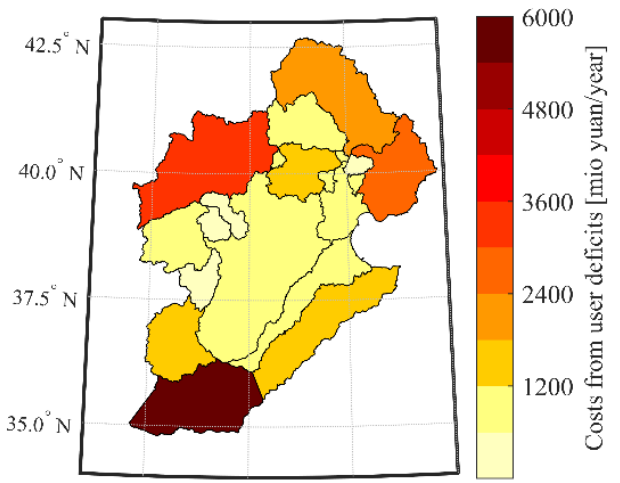

$112.5^{\circ} \mathrm{E} \quad 115.0^{\circ} \mathrm{E} \quad 117.5^{\circ} \mathrm{E} \quad 120.0^{\circ} \mathrm{E}$
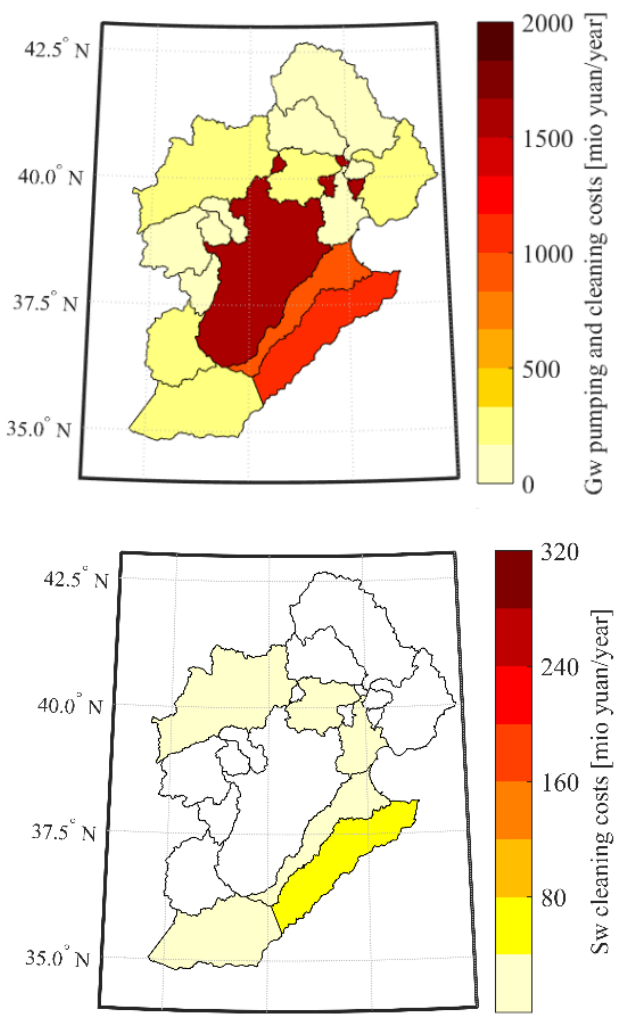

$112.5^{\circ} \mathrm{E} \quad 115.0^{\circ} \mathrm{E} \quad 117.5^{\circ} \mathrm{E} \quad 120.0^{\circ} \mathrm{E}$ 
Figure 5. Sub-basin costs. Unlimited, present and sustainable groundwater scenarios going from left to right.

\subsection{Water availability shadow prices}

From a water resources planning perspective the shadow prices are interesting, since they provide a relative comparison of where additional water sources could alleviate most costs. For Haihe River basin the spatial overview of various water resources' relative value is important to make decisions on where water resource augmentation initiatives will add relatively most value. In the unlimited groundwater scenario the highest shadow prices were found in sub-basin 3 and 9, which have some of the highest water demand deficits (Figure 6). Moving to the present scenario, the shadow prices of all water sources increased and spatial variations were evened out. This was because all surface water source shadow prices reflected the possible substitution of plain area deep aquifer pumping in the periods with no upstream water demand deficits. In the sustainable groundwater scenario the spatial variation again became more pronounced because of increased water demand deficits across the basin. A large increase in the shallow plain area groundwater shadow price was seen, and additional recharge to the shallow aquifer therefore became especially valuable when going towards a sustainable abstraction scenario. The inter-basin transfers from the SNWTP and the Yellow River in the south also reached high shadow prices. This shows how the region will become dependent on these sources of water to be able to limit groundwater overdraft, especially the SNWTP mid line with a quality class of II. What cannot be captured by the water source shadow prices are the costs faced by the river basins feeding the inter-basin transfers into Haihe River basin. These should also be accounted for in a cost-benefit analysis if water resources managers judge that increasing inter-basins transfers is the most feasible adaptation strategy. The western mountainous sub-basins had just as high surface water shadow prices. Despite a variation in surface water quality from quality class II to class IV, the western mountainous subbasins, no. 6, 7, 8, 10 and 16, all had high shadow prices under the sustainable groundwater abstraction scenario. Water resources with the best quality were not necessarily the most valuable. Water source shadow prices were the result of more complex interactions between water quality, and downstream demands, quality demands and water infrastructure. Protecting against upstream pollution and availability of water resources 
in these upstream mountainous sub-basins is therefore crucial when reaching sustainable groundwater abstraction.

Unlimited

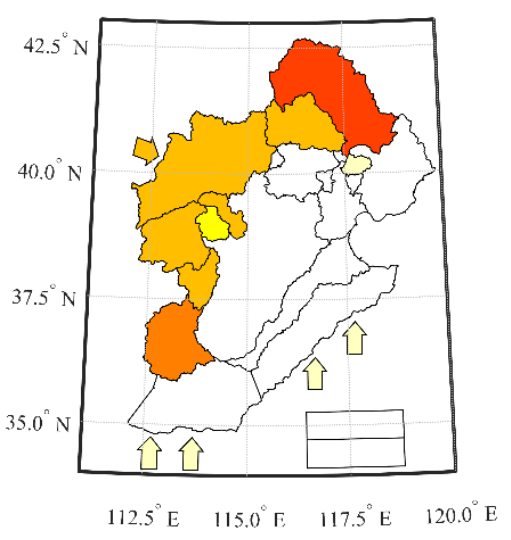

Present

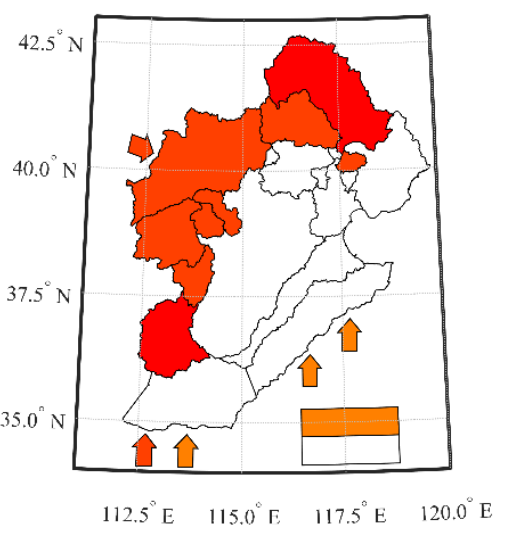

Sustainable

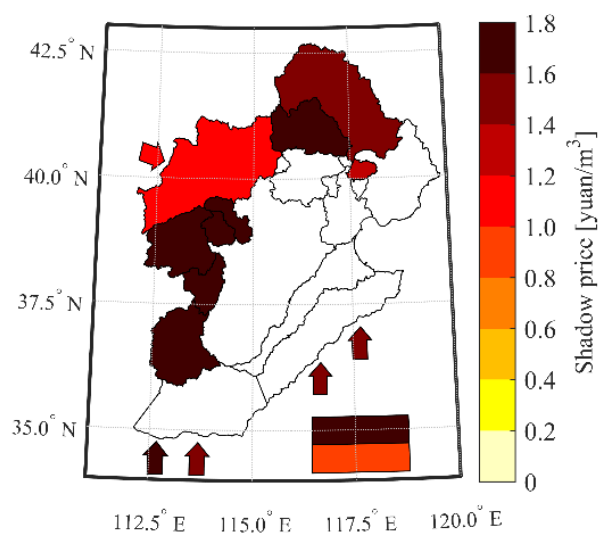

Figure 6. Average water source shadow prices. Unlimited, present and sustainable groundwater scenarios going from left to right.

The effect on shadow prices going from purely managing water resources quantities to jointly managing quantities and qualities can be seen in Figure 7. In both the unlimited and present scenario, a slight decrease was seen in most surface water shadow prices, that all have water qualities inferior to a water quality class II. These water sources all needed some level of treatment to be able to deliver qualities fit for purpose. In the sustainable groundwater scenario the effect of considering water qualities was more significant. The surface water shadow prices in sub-basin 5 decreased, when water qualities were added to the model framework, since upstream surface water allocations in sub-basin 5 need cleaning treatment. Shadow prices of the western mountainous sub-basins surface water sources all increased despite their various surface water qualities. This was a response to new plain area deficits among agricultural user groups that increased western mountainous runoff could alleviate. More of these plain area agricultural users experienced deficits, since cleaner water sources were prioritized to higher valued user groups, such as domestic purposes, which have more stringent water quality requirements. These increased agricultural deficits appeared in sub-basin 1 and 12, especially. A study by the same authors of this study (Martinsen et al., 2018) already showed the sensitivity of constraint shadow prices towards the estimated economic values of water, especially for the 
low-valued agricultural users that are most often curtailed. Local economic studies considering spatial differences in the economic value of water are therefore valuable in a spatially resolved model framework. Additionally, water availability shadow prices were highly influenced by considering water qualities. As these shadow prices determine relative values of water source augmentation, considering water qualities is likely to influence the decisions supported by this model framework.
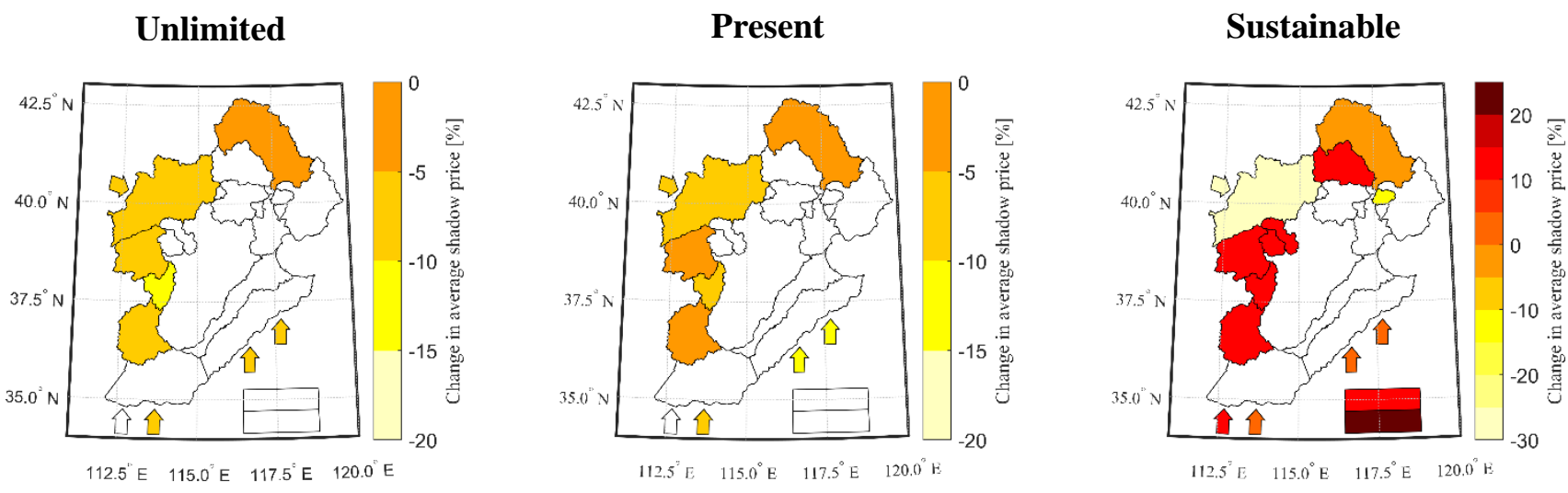

Figure 7. The effect on water source average shadow prices from introducing water qualities to the model. Showing the unlimited, present and sustainable groundwater scenarios going from left to right.

In Figure 8 each individual groundwater aquifer shadow price is compared to the average surface water shadow prices in the sub-basins connected to the respective groundwater aquifers. The mountainous groundwater aquifers generally had high water availability shadow prices, until the near-sustainable groundwater abstraction scenarios where the plain area shallow aquifer recharge became most valuable. For the western mountainous water resources, increased runoff or increased inter-basin transfers were mostly more valuable than increased groundwater recharge. For the plain area, increased inter-basin transfers were more valuable than additional recharge, from the unlimited overdraft up until the present scenario. Going towards the sustainable abstraction scenario the eastern inter-basin transfers, SNWTP east line and Yellow River east, became slightly less valuable than additional shallow aquifer recharge, and finally the value of Yellow River mid transfers decreased below the value of shallow plain aquifer recharge. A crucial water resources management strategy, in order to reach sustainable groundwater abstractions, is to ensure 
additional shallow aquifer recharge in the plain area.
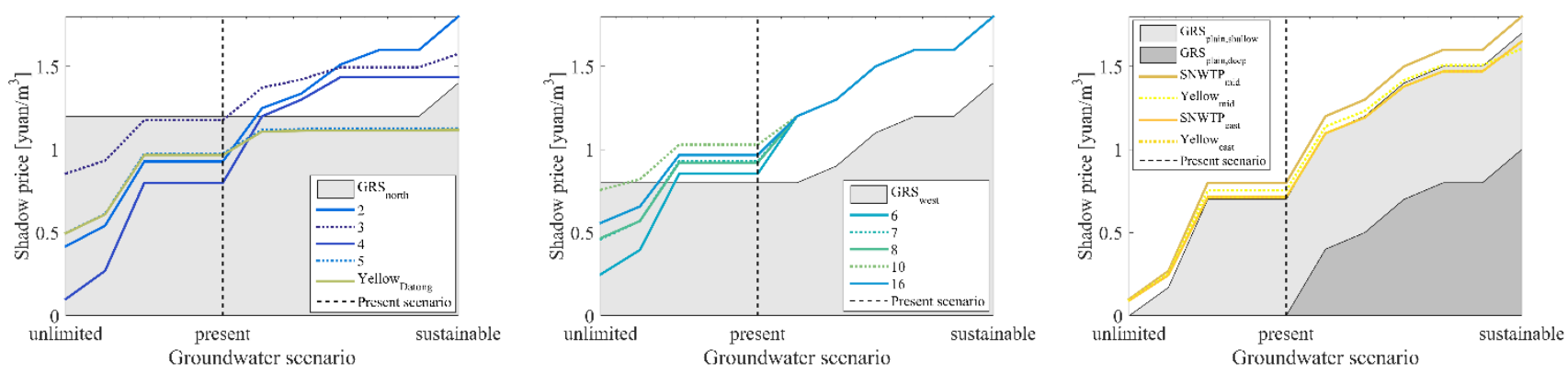

Figure 8. Groundwater and surface water average shadow prices.

\subsection{Scenario analysis}

Two scenarios were investigated that represents system changes that can improve the water resource problems in Haihe River basin. The two scenarios were:

1. Improving the water quality of the SNWTP eastern line from quality class III to quality class II

2. Managed aquifer recharge (MAR) of the plain area shallow aquifer using surplus runoff

For scenario 2, the MAR was assumed to take place in Beijing province, using a combination of different MAR facilities, as well as near the city of Shijiazhuang in Hebei province, in the dried out Hutou River bed, just downstream Gangnan and Huangbizhuang reservoirs in sub-basin 7 and 8. Infiltration capacities were based on local modelling studies by Su et al. (2013), Du et al. (2013) and Hao et al. (2014). The MAR scenarios were investigated using upstream surplus runoff, and infiltration capacities of 243 and 300 mio $\mathrm{m}^{3}$ /year for the Beijing (Hao et al. 2014) and Shijiazhuang (Su et al., 2013) MAR sites, respectively. Since MAR was performed during the wet summer months in both cases, all infiltrated surface water was assumed to recharge the groundwater aquifer.

The effect of the scenarios on total cost and the various sub-basin costs are summarized in Table 6. Both scenarios lowered the total water-associated costs in Haihe River basin. The effect of the scenarios was only compared for the sustainable groundwater abstraction scenario, since the initiatives are expected to go handin-hand with a reduced groundwater overdraft. 
Table 6. Effects of scenario 1 and 2 compared to the sustainable groundwater abstraction scenario with water qualities.

\begin{tabular}{llll}
\hline Scenario & $\begin{array}{l}\boldsymbol{\Delta} \text { total cost } \\
\text { [bio yuan/year] }\end{array}$ & $\begin{array}{l}\text { Sub-basin with highest } \\
\text { reduction in costs }\end{array}$ & $\begin{array}{l}\text { Sub-basin with highest } \\
\text { increase in costs }\end{array}$ \\
\hline SNWTP east quality & -0.14 & 1 and 12 from reduced & 13 from increased gw \\
class II & & deficits and gw pumping & pumping and cleaning costs \\
& & and cleaning costs & \\
\hline MAR using sub-basin 5, & -0.18 & 1 from reduced user & 15 from increased user \\
7 and 8 runoff & & demand deficits & demand deficits \\
\hline
\end{tabular}

Figure 9 shows the scenario effect on water availability shadow prices. The improvement of the SNWTP east water quality caused a slight increased shadow price of the eastern inter-basin transfers. The surface water sources of sub-basin 5 experienced an increase in scenario 2. The increase observed in the inter-basin transfers from SNWTP east and the Yellow River inter-basin transfers at the southern fringe of Haihe River basin was insignificantly small.
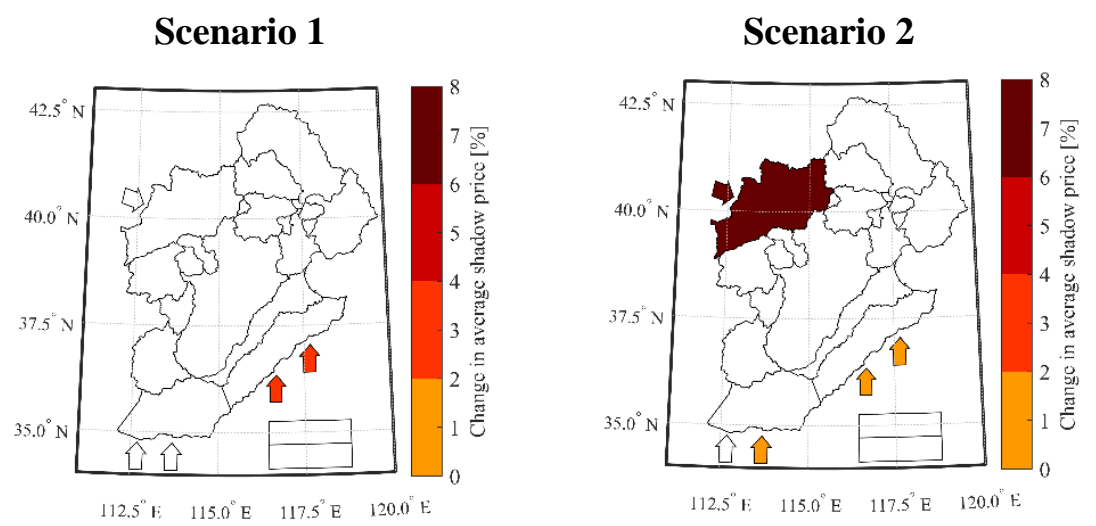

Figure 9. Change in shadow prices under sustainable groundwater abstractions from scenario 1 and 2.

The change in sub-basin costs from introducing each of the two scenarios showed the redistribution of costs occurring within Haihe River basin (Figure 10). In scenario 1 the sub-basins receiving the eastern inter-basin transfers had a high reduction in costs from deficits and groundwater pumping and cleaning as an effect of the improved surface water quality of the SNWTP east line water transfers. They were now able to serve 
higher valued users with clean surface water and reduce costs of pumping groundwater. More groundwater was pumped for the plain area sub-basin 13, and the end-receiver of the SNWTP east water, sub-basin 15, experienced an increased demand deficit and a decreased groundwater pumping. Using MAR in scenario 2 caused an overall decrease in costs originating from demand deficits, especially in sub-basin 1. Increase in demand deficits were seen in sub-basins 11,12 and 15, which are downstream the sources of runoff that is now infiltrated. A general increase in groundwater pumping costs was also observed, as expected with additional water sources stored in groundwater aquifer. Both scenarios showed no change in surface water 
cleaning costs.

Scenario 1
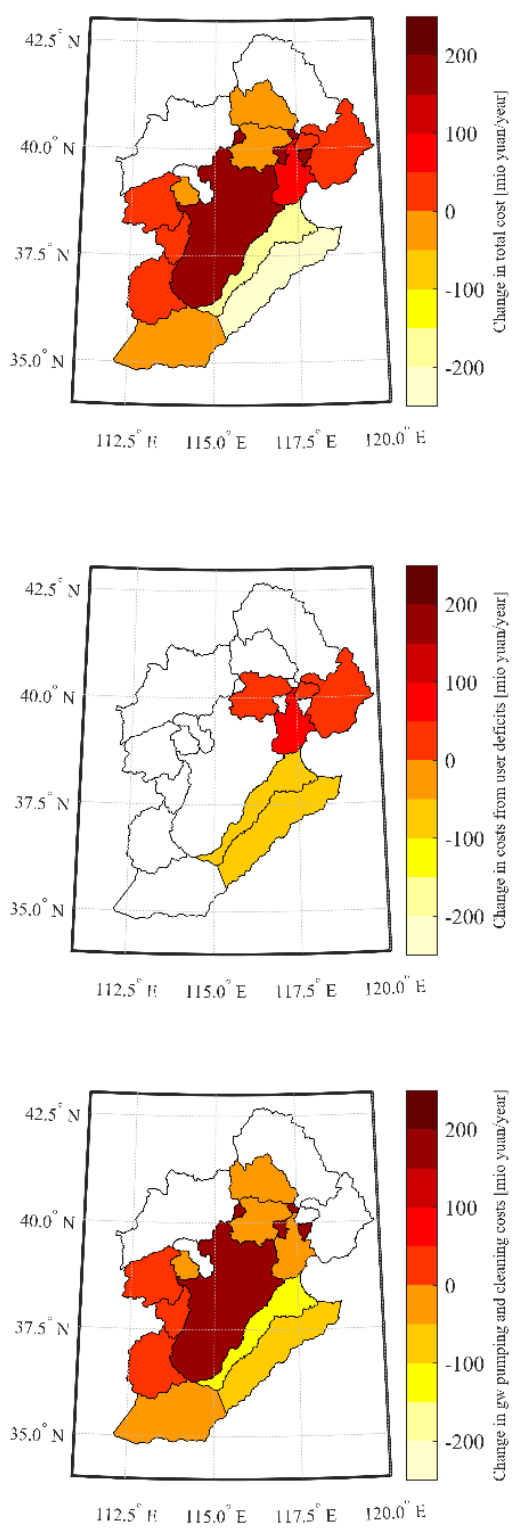

Scenario 2
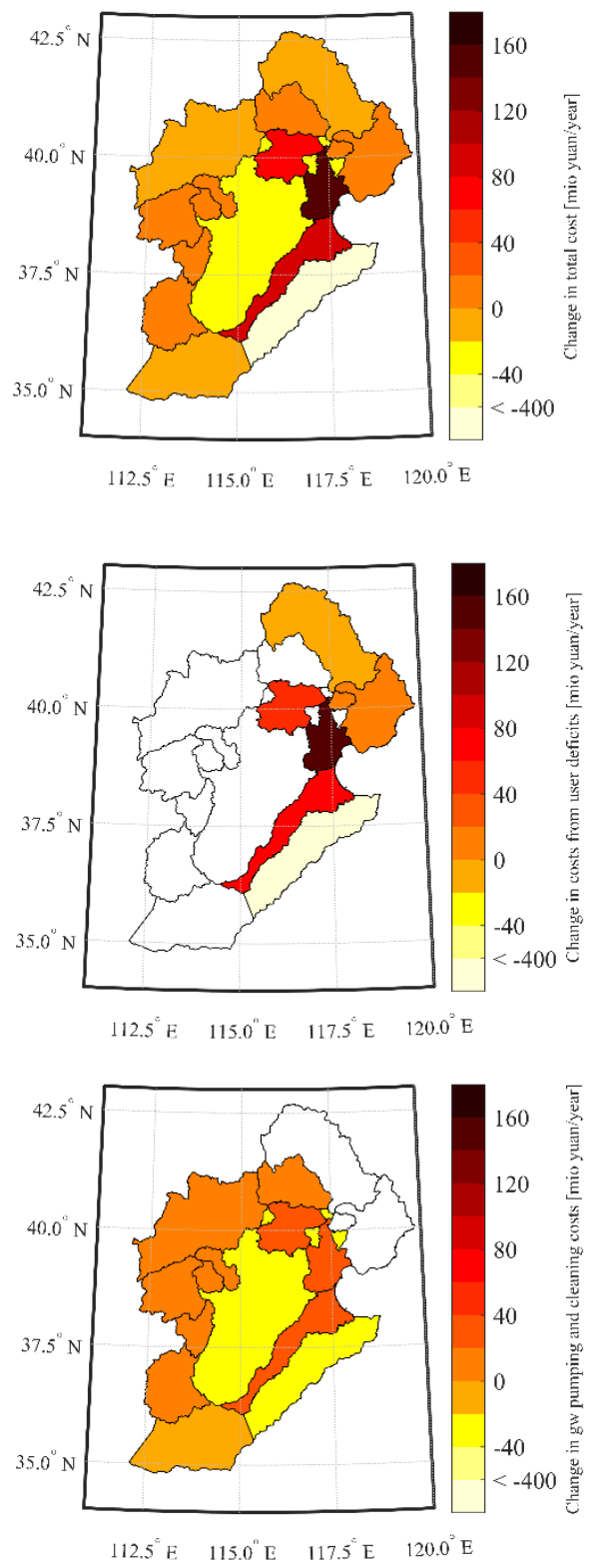

Figure 10. Change in sub-basin costs from introducing scenario 1 and 2 under sustainable groundwater abstractions.

The results of this study's scenario analysis explore the overall cost reduction from an allocation perspective, but cannot capture local increases in groundwater tables. It further assumes a perfect substitution of groundwater resources between all connected plain area users. In reality, the effect on the groundwater table is local. The MAR initiative should therefore be backed up by local hydrogeological investigations as well as 
more detailed groundwater modeling studies. The choice of a simple groundwater aquifer representation in this study is a conscious choice. The attributes of the model as perfect foresight, basin scale water resources management and uncertainties in local groundwater abstractions and recharges argues for a more robust model for water resources planning, with groundwater resources lumped into total storages, ignoring spatiotemporal dynamics in the groundwater aquifers.

\subsection{Model limitations}

A major concern in water resources management is the uncertainty of future water availability. Flood control and droughts are most often the two main objectives of water management. Flood incidents often happen on a daily time scale, whereas drought is a long-term incident. The model results presented in this study were optimized over an eight-year historic meteorological time series that captures all climate variability within the period of 2007-2015. Several studies have also shown that the future climate of Haihe River basin will be influenced by increasing temperatures and alterations in precipitation patterns (Guo et al., 2002; Lu et al., 2013; Chu et al., 2010). The model results do not capture future climate changes, and only quantify costs for similar climate variabilities as for the historic period 2007-2015. The model framework further assumes perfect foresight over the full planning period. In reality, water planners and managers will not have perfect foresight, but will be limited by the extent of available forecasting products. Unforeseen future droughts will lead to great losses in agriculture and risks of urban water supply cut-offs. Nothing is unforeseen when optimizing with perfect foresight. Numerous stochastic optimization approaches that take into account the uncertainty of weather and climate have been presented, as discussed by Labadie (2004). The focus of this study is to compare performance of different projects and scenarios and not on operational decision support. On this basis, the perfect foresight assumption can be justified. The assumption of perfect foresight will underestimate the true water associated costs and cost estimates should be regarded as lower boundaries.

All input data and parameterization of the optimization model are exogenous to the model framework. This means that hydrological simulations, water demands and water values are inputs to the optimization model, and do not have any non-linear dependencies with the allocation scheme of the optimization model results. This highly enhances the computational efficiency of the model. On the other hand, there is a risk of losing 
insight into the effects of changed water allocations and system changes. The optimization model cannot capture effects on groundwater recharge from changes in agricultural irrigation practices, or in-stream flow and quality from urban and industrial return flows and agricultural nutrient seepage. On the other hand, this limits computational resources and uncertainties introduced from parameterization and modelling of these interactions. In good water management practice, any major system change should be accounted for, and the model updated with new information. Adaptation towards more sustainable groundwater allocations will likely result in major system changes. The model results must therefore be evaluated as "where do we go from now" decision support.

\section{Conclusion}

The proposed model framework of joint optimization of water allocation and water quality management revealed economic trade-offs from limiting groundwater overdraft and mapped out water availability shadow prices in Haihe River basin. The relative cost of reaching sustainable groundwater allocations, compared to a scenario mimicking present water management, was 12.2 bio yuan/year. The majority of the costs originated from user demand deficits, especially in the sub-basins not well connected by water infrastructure (sub-basin 9 and 15). Deficit costs were also high in sub-basin 3 and 5 with bad surface water qualities. The plain area sub-basins further became more dependent on the surface water runoff from the mountainous regions and the costs of cleaning polluted surface water shifted to the downstream plain area sub-basins. The water availability shadow prices were highly affected by adding water quality management to the model framework, implying that decision-making in water resources management can be altered from considering water qualities. In order to limit groundwater overdraft, the most valuable surface water sources were seen to be the inter-basin transfers, SNWTP and from the Yellow River, at the southern fringe of the Haihe River basin. Equally important were many of the mountainous surface water runoff with different water qualities ranging from a quality class of II to IV. The shadow prices of water availability ware seen to depend on a complex interaction of both water quality and downstream demands, quality demands and water infrastructure. A scenario analysis of groundwater recharge of surplus mountainous runoff, was shown to 
lower total water associated costs within Haihe River basin. It can be recommended as a feasible strategy towards limiting groundwater overdraft, if managed in the right way.

Acknowledgement. Liu Suxia and Mo Xingguo were supported by the National Key Research and Development Program of China (No.2016YFC0401402) and National Natural Science Foundation of China (No.41471026). The author would further like to thank the Sino-Danish Center for Education and Research for financial support.

\section{References}

Allen, Richard G., L.S. Pereira, D. Raes, and M. Smith. 1998. “Crop Evapotranspiration: Guidelines for Computing Crop Requirements.” Irrigation and Drainage Paper No. 56, FAO, no. 56: 300. doi:10.1016/j.eja.2010.12.001.

AQUATOOL. 2018. “AQUATOOL Manuals.” https://aquatool.webs.upv.es/aqt/en/manuals/.

Bao, Zhenxin, Jianyun Zhang, Guoqing Wang, Guobin Fu, Ruimin He, Xiaolin Yan, Junliang Jin, Yanli Liu, and Aijing Zhang. 2012. “Attribution for Decreasing Streamflow of the Haihe River Basin, Northern China: Climate Variability or Human Activities?” Journal of Hydrology 460-461: 117-29. doi:10.1016/j.jhydrol.2012.06.054.

Bright, Eddie A, Amy N Rose, Marie L Urban, and Jacob J McKee. 2017. “LandScan 2016.” LandScan. Oak Ridge, TN: Oak Ridge National Laboratory SE - July 1, 2017. http://www.ornl.gov/landscan/.

Cai, Ximing, Daene C McKinney, and Leon S Lasdon. 2001. “Solving Nonlinear Water Management Models Using a Combined Genetic Algorithm and Linear Programming Approach.” Advances in Water Resources 24 (6): 667-76. doi:10.1016/S0309-1708(00)00069-5.

Cao, Guoliang, Chunmiao Zheng, Bridget R. Scanlon, Jie Liu, and Wenpeng Li. 2013. "Use of Flow 
Modeling to Assess Sustainability of Groundwater Resources in the North China Plain.” Water Resources Research 49 (1): 159-75. doi:10.1029/2012WR011899.

Cheng, Wei-Chen, Nien-Sheng Hsu, Wen-Ming Cheng, and William W.-G. Yeh. 2009. “A Flow Path Model for Regional Water Distribution Optimization.” Water Resources Research 45 (9): n/a-n/a. doi:10.1029/2009WR007826.

China Meteorological Agency. 2017. "Dataset of Daily Climate Data from Chinese Surface Stations for Global Exchange (V3.0).” http://data.cma.cn/en/?r=data/detail\&dataCode=SURF_CLI_CHN_MUL_DAY_CES_V3.0.

China Water Risk. 2017. “New ‘Water Ten Plan’ to Safeguard China’s Waters.” http://chinawaterrisk.org/notices/new-water-ten-plan-to-safeguard-chinas-waters/.

Chu, J T, J Xia, C.-Y Xu, and V P Singh. 2010. "Statistical Downscaling of Daily Mean Temperature, Pan Evaporation and Precipitation for Climate Change Scenarios in Haihe River, China.” doi:10.1007/s00704-009-0129-6.

Davidsen, Claus, Suxia Liu, Xingguo Mo, Peter E. Holm, Stefan Trapp, Dan Rosbjerg, and Peter BauerGottwein. 2015. “Hydroeconomic Optimization of Reservoir Management under Downstream Water Quality Constraints.” Journal of Hydrology 529 (October): 1679-89. doi:10.1016/j.jhydrol.2015.08.018.

Davidsen, Claus, Suxia Liu, Xingguo Mo, Dan Rosbjerg, and Peter Bauer-Gottwein. 2016. "The Cost of Ending Groundwater Overdraft on the North China Plain.” Hydrology and Earth System Sciences 20 (2). Copernicus GmbH: 771-85. doi:10.5194/hess-20-771-2016.

DHI. 2018. “DHI MIKE HYDRO BASIN.” https://www.mikepoweredbydhi.com/products/mike-hydrobasin.

Du, Shanghai, Xiaosi Su, and Wenjing Zhang. 2013. “Effective Storage Rates Analysis of Groundwater 
Reservoir with Surplus Local and Transferred Water Used in Shijiazhuang City, China.” Water and Environment Journal 27 (2): 157-69. doi:10.1111/j.1747-6593.2012.00339.x.

Feng, Wei, Min Zhong, Jean-Michel Lemoine, Richard Biancale, Hou-Tse Hsu, and Jun Xia. 2013.

"Evaluation of Groundwater Depletion in North China Using the Gravity Recovery and Climate Experiment (GRACE) Data and Ground-Based Measurements.” Water Resources Research 49 (4): 2110-18. doi:10.1002/wrcr.20192.

Gan, Hong, Lin Wang, Hong-zhen Ni, and Chun-ling Zhang. 2008. “Assessment on Methods for Calculating Economic Value of Water.” Shuili Xuebao 39 (11): 1160-66. In Chinese

Guo, Shenglian, Jinxing Wang, Lihua Xiong, Aiwen Ying, and Dingfang Li. 2002. “A Macro-Scale and Semi-Distributed Monthly Water Balance Model to Predict Climate Change Impacts in China.” Journal of Hydrology 268 (1-4): 1-15. doi:10.1016/S0022-1694(02)00075-6.

H2O China. 2000. “H2O China Water Prices.” http://price.h2o-china.com/. In Chinese

Hao, Qichen, Jingli Shao, Yali Cui, and Zhenhua Xie. 2014. “Applicability of Artificial Recharge of Groundwater in the Yongding River Alluvial Fan in Beijing through Numerical Simulation.” Journal of Earth Science 25 (253): 575-86. doi:10.1007/s12583-014-0442-6.

Harou, Julien J., Manuel Pulido-Velazquez, David E. Rosenberg, Josué Medellín-Azuara, Jay R. Lund, and Richard E. Howitt. 2009. "Hydro-Economic Models: Concepts, Design, Applications, and Future Prospects.” Journal of Hydrology 375 (3-4). Elsevier B.V.: 627-43. doi:10.1016/j.jhydrol.2009.06.037.

Harou, Julien J, Josué Medellín-Azuara, Tingju Zhu, Stacy K Tanaka, Jay R Lund, Scott Stine, Marcelo A Olivares, and Marion W Jenkins. 2010. “Economic Consequences of Optimized Water Management for a Prolonged, Severe Drought in California.” Water Resources Research 46 (5): 5522. doi:10.1029/2008WR007681.

Hsieh, Cheng-Daw, and Wan-Fa Yang. 2007. “Optimal Nonpoint Source Pollution Control Strategies for a 
Reservoir Watershed in Taiwan.” Journal of Environmental Management 85: 908-17.

doi:10.1016/j.jenvman.2006.10.022.

Huang, Y, Y P Li, X Chen, and Y G Ma. 2012. “Optimization of the Irrigation Water Resources for Agricultural Sustainability in Tarim River Basin, China.” Agricultural Water Management 107: 74-85. doi:10.1016/j.agwat.2012.01.012.

IPA. 2006. “China Water Pollution Map.” http://wwwen.ipe.org.cn/index.html.

Kendy, Eloise, Pierre G?rard-Marchant, M. Todd Walter, Yongqiang Zhang, Changming Liu, and Tammo S. Steenhuis. 2003. “A Soil-Water-Balance Approach to Quantify Groundwater Recharge from Irrigated Cropland in the North China Plain.” Hydrological Processes 17 (10). John Wiley \& Sons, Ltd.: 201131. doi:10.1002/hyp.1240.

Labadie, John W. 2004. “Optimal Operation of Multireservoir Systems: State-of-the-Art Review.” Journal of Water Resources Planning and Management 130 (2): 93-111. doi:10.1061/(ASCE)07339496(2004)130:2(93).

Lehner, Bernhard, Catherine Reidy Liermann, Carmen Revenga, Charles Vörösmarty, Balazs Fekete, Philippe Crouzet, Petra Döll, et al. 2011. “High-Resolution Mapping of the World’s Reservoirs and Dams for Sustainable River-Flow Management.” Frontiers in Ecology and the Environment 9 (9). Wiley-Blackwell: 494-502. doi:10.1890/100125.

Liu, Jie, Chunmiao Zheng, Li Zheng, and Yuping Lei. 2008. “Ground Water Sustainability: Methodology and Application to the North China Plain.” Ground Water 46 (6): 897-909. doi:10.1111/j.17456584.2008.00486.x.

Loucks, Daniel P., and Eelco van Beek. 2005. “Water Quality Modelling and Prediction.” In Water Resources Systems Planning and Management - An Introduction to Methods, Models and Applications, 374-425. United Nations Educational. 
Lu, G.-H.a, H.a Xiao, Z.-Y.a Wu, S.-L.b Zhang, and Y.b Li. 2013. “Assessing the Impacts of Future Climate Change on Hydrology in Huang-Huai-Hai Region in China Using the PRECIS and VIC Models.” Journal of Hydrologic Engineering 18 (9): 1077-87. doi:10.1061/(ASCE)HE.1943-5584.0000632.

MacEwan, Duncan, Mesut Cayar, Ali Taghavi, David Mitchell, Steve Hatchett, and Richard Howitt. 2017. “Hydroeconomic Modeling of Sustainable Groundwater Management.” Water Resources Research, March. doi:10.1002/2016WR019639.

Martinsen, Grith, Suxia Liu, Xingguo Mo, and Peter Bauer-Gottwein. 2018. “Optimizing Water Resources Allocation in the Haihe River Basin under Groundwater Sustainability Constraints.” Journal of Geographical Sciences.

Medellin-Azuara, Josue, Jon Herman, Jay R Lund, Richard E Howitt, and Marion W Jenkins. 2018. “CALVIN Project Overview.” Evaluation. Accessed September 25. https://watershed.ucdavis.edu/shed/lund/CALVIN/.

Ministry of Environmental Protection. 2002. “Environmental Quality Standards for Sw - 3838-2002.Pdf.” http://english.mep.gov.cn/standards_reports/standards/water_environment/quality_standard/200710/t20 071024_111792.htm.

Ministry of Environmental Protection. 2011. "National Groundwater Pollution Prevention and Control Plan 2011-2020.”. In Chinese

Ministry of Environmental Protection. 2016a. “2016 State of Environment Report.”. In Chinese

Ministry of Environmental Protection. 2016b. “National Surface Water Quality Report 2016 - October.” http://www.mep.gov.cn/hjzl/shj/dbsszyb/. In Chinese

Ministry of Water Resources. 2011. “Hydrological Data of Haihe River Basin.” In Annual Hydrological Report. Bureau of Hydrology. In Chinese

National Bureau of Statistics of China. 2015. “China Statistical Yearbook - Water Supply and Water Use.” 
http://www.stats.gov.cn/tjsj/ndsj/2015/indexeh.htm.

NSBD. 2001a. "Brief Introduction of the Planning of the Eastern Route Project of the South to North Water Transfer Project.” http://www.nsbd.gov.cn/zx/gcgh/200308/t20030825_195172.html. In Chinese

NSBD. 2001b. "Brief Introduction of the Planning of the Middle Route Project of the South to North Water Transfer Project.” http://www.nsbd.gov.cn/zx/gcgh/200308/t20030825_195173.html. In Chinese

Peña-Haro, Salvador, Manuel Pulido-Velazquez, and Andrés Sahuquillo. 2018. “A Hydro-Economic Modelling Framework for Optimal Management of Groundwater Nitrate Pollution from Agriculture.” Journal of Hydrology 373: 193-203. Accessed October 24. doi:10.1016/j.jhydrol.2009.04.024.

Pereira, M V F, and L M V G Pinto. 1991. "Multi-Stage Stochastic Optimization Applied to Energy Planning.” Mathematical Programming. Vol. 52. http://production.datastore.cvt.dk/filestore?oid=5485984859d824b742354afa\&targetid=5485984859d8 24b742354afc.

Pulido-velazquez, Manuel, Manuel Pulido-velázquez, Joaquín Andreu, and Andrés Sahuquillo. 2006. "Economic Optimization of Conjunctive Use of Surface Water and Groundwater at the Basin Scale Economic Optimization of Conjunctive Use of Surface Water and Groundwater at the Basin Scale,” no. December 2015. doi:10.1061/(ASCE)0733-9496(2006)132.

Shen, Dajun. 2012. “Water Quality Management in China Water Quality Management in China,” no. October 2013: 37-41. doi:10.1080/07900627.2012.669079.

Shu, Yunqiao, Karen G Villholth, Karsten H Jensen, Simon Stisen, and Yuping Lei. 2012. “Integrated Hydrological Modeling of the North China Plain : Options for Sustainable Groundwater Use in the Alluvial Plain of Mt . Taihang.” Journal of Hydrology 464-465. Elsevier B.V.: 79-93. doi:10.1016/j.jhydrol.2012.06.048.

Steinshouer, D W, J Qiang, P J McCabe, and R T Ryder. 1997. “Maps Showing Geology, Oil and Gas 
Fields, and Geologic Provinces of the Asia Pacific Region.” USGS Open File Report.

Su, Xiaosi, Wei Xu, and Shanghai Du. 2013. “In Situ Infiltration Test Using a Reclaimed Abandoned River Bed: Managed Aquifer Recharge in Shijiazhuang City, China.” doi:10.1007/s12665-013-2893-y.

Tan, Debra, Feng Hu, Hubert Thieriot, and Dawn McGregor. 2015. “Towards a Water and Energy Secure China Tough Choices Ahead in Power Expansion with Limited Water Resources.” China Water Risk. http://chinawaterrisk.org/notices/towards-a-water-energy-secure-china/.

Wada, Y., D. Wisser, and M. F. P. Bierkens. 2014. “Global Modeling of Withdrawal, Allocation and Consumptive Use of Surface Water and Groundwater Resources.” Earth System Dynamics 5 (1). Copernicus GmbH: 15-40. doi:10.5194/esd-5-15-2014.

Wang, Xiao-jun, Jian-yun Zhang, Zhi-feng Yang, Shamsuddin Shahid, Rui-min He, Xing-hui Xia, and Hong-wei Liu. 2015. “Historic Water Consumptions and Future Management Strategies for Haihe River Basin of Northern China.” Mitigation and Adaptation Strategies for Global Change 20 (3): 37187. doi:10.1007/s11027-013-9496-5.

Wang, Xiaoling, Yuefeng Sun, Lingguang Song, and Chuanshu Mei. 2009. “An Eco-Environmental Water Demand Based Model for Optimising Water Resources Using Hybrid Genetic Simulated Annealing Algorithms. Part I. Model Development.” Journal of Environmental Management 90 (8). Elsevier Ltd: 2628-35. doi:10.1016/j.jenvman.2009.02.008.

Weng, S. Q., G. H. Huang, and Y. P. Li. 2010. “An Integrated Scenario-Based Multi-Criteria Decision Support System for Water Resources Management and Planning - A Case Study in the Haihe River Basin.” Expert Systems with Applications 37 (12): 8242-54. doi:10.1016/j.eswa.2010.05.061.

World Bank. 2001. “Agenda for Water Sector Strategy for North China, Volume 2, Main Report, Report No. 22040-CHA CHINA” 2 (22040). http://citeseerx.ist.psu.edu/viewdoc/download;jsessionid=651D389F1C576013361B5781FBCF78C3?d oi=10.1.1.99.9800\&rep=rep1\&type=pdf. 
Zhang, Lu. 2008. "Water Balance Modeling over Variable Time Scales Based on the Budyko Framework Model Development and Testing Water Balance Modeling over Variable Time Scales Based on the Budyko Framework - Model Development and Testing,” no. October 2016. doi:10.1016/j.jhydrol.2008.07.021. 